\title{
POTENCIAL ENERGÉTICO DE COMBUSTÍVEIS FLORESTAIS EM CULTIVOS DE Pinus elliottii NO SUL DO BRASIL
}

\author{
THE ENERGETIC POTENTIAL OF FOREST FUELS IN Pinus elliottii STANDS IN \\ SOUTHERN BRAZIL
}

\author{
Aires Afonso Mbanze ${ }^{1}$ Dimas Agostinho da Silva ${ }^{2}$ Alexandre França Tetto ${ }^{2}$ José Fernando \\ Pereira $^{3}$ Antonio Carlos Batista ${ }^{2}$
}

\begin{abstract}
RESUMO
De modo a determinar o potencial energético dos combustíveis florestais em cultivos de Pinus elliottii, foi analisada a melhor época de coleta deste material em função da umidade, disponibilidade, Poder Calorífico Superior (PCS) e composição química imediata, em parcelas estabelecidas e monitoradas durante um ano na estação experimental de Rio Negro, estado do Paraná. No delineamento experimental, as estações do ano (inverno, verão, primavera e outono) foram consideradas blocos, enquanto as seguintes classes de diâmetro do material combustível os tratamentos: $\mathrm{AA}$, na camada superior; $\mathrm{AB}$, na camada intermediária; $\mathrm{AC}$, na camada inferior, todas com material de diâmetro até $0,7 \mathrm{~cm}$; e a $\mathrm{B}$, com material de 0,71 a 2,5 $\mathrm{cm}$. No campo, foi determinada a massa (base úmida) do material coletado nas subparcelas de $900 \mathrm{~cm}^{2} \mathrm{e}$ posteriormente levadas ao laboratório da Universidade Federal do Paraná (UFPR), no qual se procederam as análises referentes à umidade (base seca), Poder Calorífico Superior (PCS) e composição química imediata. Foi recorrido à análise de variância (ANOVA) e ao Teste de Tukey para comparação das épocas (blocos) e das diferentes classes de material combustível (tratamentos). Com baixo teor de umidade e maior quantidade de material disponível, observou-se pelo teste de médias, para todas as classes de material, que o inverno foi a melhor época de coleta. Para a mesma época de coleta foi possível observar pelo PCS e análise da composição química imediata que as médias das classes AA e B foram estatisticamente superiores em relação às demais. A manta apresentou densidade energética considerável $\left(12.275,42.10^{5} \mathrm{kcal} \mathrm{ha}^{-1}\right)$ para conversão em bioenergia. Pelos resultados do presente estudo observou-se que existe potencial para aproveitamento de resíduos florestais como fonte de energia limpa e renovável.
\end{abstract}

Palavras-chave: combustíveis florestais; energia da biomassa; estações do ano.

\begin{abstract}
In order to determine the potential energy of forest fuels in Pinus elliottii stands, we investigated the best season to collect fuel material considering fuel availability, moisture content, Higher Calorific Value (HCV) and immediate chemical composition, from the plots established and monitored during one year at Rio Negro Research station, Paraná state, Brazil. The year's seasons (winter, summer, spring and autumn) were considered as experimental blocks while the diameter of the materials (AA, $\mathrm{AB}$ and $\mathrm{AC}$ ) as treatments. These treatments were pre-defined in the following diameter classes: $\mathrm{AA}$, in the upper layer; $\mathrm{AB}$, in the intermediate layer; $\mathrm{AC}$, in the lower layer, all materials up to $0,7 \mathrm{~cm}$; and $\mathrm{B}$, with material of 0.71 to 2.5 $\mathrm{cm}$. The fuel material of all year's seasons was collected in sub plots of $900 \mathrm{~cm}^{2}$, weighted in the field and taken to the laboratory of the Federal University of Paraná (UFPR) to carry out the rest of analyzes

1 Engenheiro Florestal, MSc., Investigador Assistente do Departamento de Ambiente e Conservação da Naturais na Universidade Lúrio, Faculdade de Ciências Agrárias, Campus Universitários de Unango/Sanga, Moçambique. ambanze@unilurio.ac.mz

2 Engenheiro Florestal, Dr., Professor do Departamento de Ciências Florestais, Universidade Federal do Paraná, Av. Lothário Meissner, 632, CEP 80210-170,Curitiba (PR), Brasil. batistaufpr@ufpr.br / tetto@ufpr.br / dimass@ ufpr.br

3 Engenheiro Florestal, Dr., Professor da Universidade Federal do Tocantins, Campus Gurupi, Rua Badejós, Cháca ras 69 / 72, Lt. 07, CEP 77402-970, Gurupi (TO), Brasil. jose.pereira@mail.uft.edu.br
\end{abstract}


including: moisture on the dry basis, fuel availability, Higher Calorific Value (HCV) and immediate chemical composition. Analyses of variance (ANOVA) and Tukey test were performed to compare the differences between seasons and material classes. Together with low moisture content and greater fuel availability, the mean test showed that, for all material classes, the winter was the best season to collect forest fuel material of Pinus elliottii stands. The results also showed that, for immediate composition and HCV, the mean class AA and B were statistically superior than the other classes. The fuel loading had a considerable density of energetic $\left(12,275.42 \cdot 10^{5} \mathrm{kcal} \mathrm{ha}^{-1}\right)$ for bioenergy conversion and utilization.

Keywords: biomass energy; forestry fuels; year's season.

\section{INTRODUÇÃO}

Em 2040, o consumo mundial de energia aumentará 25\%, sobretudo no Médio Oriente, Ásia e América (ENERGY INFORMATION ADMINISTRATION, 2017), sendo que as de fontes renováveis sofrerão um aumento considerável, comparativamente às não renováveis (AL-HAMAMRE et al., 2017; ENERGY INFORMATION ADMINISTRATION, 2017). Cabe destacar que, na atualidade, uma em cada cinco unidades consumidas provém de fontes renováveis, porém, estima-se que até 2030, a margem estará em aproximadamente $36 \%$. Isso se justifica por serem a principal opção para ampliar seu acesso, serem mais econômicas, além de confiáveis e limpas; prova disso é que mais de 170 países se comprometeram em aumentar seu uso e quase 150 promulgaram políticas para acelerar investimentos em tecnologias para a produção das mesmas (INTERNATIONAL RENEWABLE ENERGY AGENCY, 2017).

Embora, por vários séculos, a silvicultura tenha atendido às necessidades de madeira para fins industriais, principalmente para a produção de celulose e papel, desde o começo dos anos 80 têmse difundido novos padrões de formação de cultivos homogêneos, com vistas à produção de energia da biomassa (NOGUEIRA et al., 2000), devido à importância da matéria orgânica no fornecimento de fontes alternativas de energias limpas e renováveis (ENERGY INFORMATION ADMINISTRATION, 2013). De fato, a biomassa tem gradualmente se tornado uma opção atrativa de energia (WU et al., 2017), dada a sua versatilidade, podendo ser usada para suprir uma variedade de necessidades, incluindo a geração de eletricidade, abastecimento de veículos na forma de biocombustíveis, aquecimento ou fornecimento de calor para instalações domésticas e industriais. O seu potencial inclui animais, plantas e resíduos florestais (TOKLU, 2017), tendo sido objeto de muitos estudos (EROL; HAYKIRI-ACMA; KÜÇÜKBAYRAK, 2010; AL-HAMAMRE et al., 2017; ÖZYUĞURAN; YAMAN, 2017; WU et al., 2017), ainda que tenham sido poucos os que investigaram em material combustível proveniente de plantios de Pinus.

A biomassa é considerada como sendo todo o material vegetal produzido pela fotossíntese, incluindo os diversos produtos e subprodutos derivados do mesmo processo, tais como: florestas, culturas, resíduos agrícolas, dejetos animais e matéria orgânica que é contida nos rejeitos industriais e urbanos, voltada para produção de fontes alternativas de energia (NOGUEIRA; LORA, 2002; ROSILLO-CALLE; BAJAY; ROTHMAN, 2005; BRASIL, 2007; CORTEZ; LORA; GÓMEZ, 2008; AL-HAMAMRE et al., 2017; PAHLA et al., 2017). Ela é tida como a segunda fonte de energia mais utilizada no Brasil, fazendo do país um dos poucos no mundo com potencial para substituir combustíveis fósseis pelos renováveis (CORTEZ; LORA; GÓMEZ, 2008). A energia proveniente dela pode ser classificada em função da origem da matéria que a constitui, podendo ser: florestal, agrícola ou de rejeitos urbanos (NOGUEIRA; LORA, 2002). A primeira, objeto do presente estudo, pode ser definida como sendo o material advindo da colheita florestal (galhos, folhas, tocos e raízes), os resíduos gerados no processamento da madeira e a matéria oriunda de florestas energéticas (SOUZA, 2010). Nessa classificação, os combustíveis florestais são referenciados de forma implícita, embora estes constituam uma fração considerável desse tipo de energia.

A área total de árvores plantadas no Brasil totalizou 7,8 milhões de hectares em 2015, sendo 5,6 (71,79\%) e 1,6 (20,51\%) milhões ocupados por cultivos de Eucalyptus e Pinus, respectivamente (INDÚSTRIA BRASILEIRA DE ÁRVORES, 2016). O gênero Eucalyptus continua a ter preferência em plantios comerciais, devido ao seu curto período de rotação, ao contrário de Pinus, que é mais usado como principal fonte de energia para as empresas, devido ao seu poder energético (CORTEZ; LORA; GÓMEZ, 2008). Os cultivos florestais, particularmente as plantações de Pinus, estão todos os anos propensos a incêndios, os quais consomem grandes quantidades de material combustível que poderiam ser convertidos 
em biomassa, minimizando as perdas econômicas e os danos causados ao ambiente.

Um dos principais desafios que o setor florestal brasileiro enfrentará nos próximos anos, estará relacionado com o suprimento da demanda de biomassa, considerando-se sua sazonalidade (CORTEZ; LORA; GÓMEZ, 2008). Assim sendo, a conversão de combústiveis florestais dos cultivos de Pinus em bioenergia irá desempenhar um importante papel no futuro forncecimento de energias limpas e contribuirá para redução da poluição atmosférica, visto que a ocorrência de incêndios em cultivos florestais libera quantidades consideráveis de gás carbônico (FULLER, 1991; CHOI; CHAMG; PARK, 2006). A emissão de gases tóxicos, devido aos incêndios florestais, poderá comprometer as vantagens comparativas e competitivas que a biomassa possui em relação aos outros tipos de energias renováveis, bem como a sua oferta no mercado. Por essa razão, nesse estudo, avaliou-se a possibilidade de conversão de combustíveis florestais para bioenergia, em cultivos de Pinus elliottii, considerando aspectos relacionados a sua disponibilidade nas diferentes épocas do ano, poder calorífico e composição química imediata.

\section{MATERIAL E MÉTODOS}

\section{Localização e caracterização da área de estudo}

A estação experimental da Universidade Federal do Paraná (UFPR), na qual foi conduzido o presente estudo, localiza-se nas margens da rodovia BR-116, a aproximadamente $5 \mathrm{~km}$ da sede do município do Rio Negro, no segundo planalto paranaense, sudeste do estado, nas coordenadas $26^{\circ} 06^{\prime}$ sul e $49^{\circ} 47^{\prime}$ oeste, com altitude média de $780 \mathrm{~m}$. Pela classificação de Köppen, o clima da região é temperado úmido $(\mathrm{Cfb})$, com temperatura média do mês mais quente de $22^{\circ} \mathrm{C}$, verificando-se a ocorrência de mais de cinco geadas por ano (BATISTA, 1995; MAACK, 2002). A estação experimental ocupa uma área de aproximadamente 120 ha, sendo que grande parte é composta por cultivos florestais. Para a realização do trabalho, foi selecionada uma área de Pinus elliottii, implantada no ano de 1984, com um espaçamento inicial de 2 × 2,5 m, não tendo ocorrido nenhum tratamento cultural desde então.

\section{Amostragem}

O experimento totalizou uma área de $200 \mathrm{~m}^{2}$, dividido em quatro faixas, posicionadas entre as linhas de plantio (sentido leste-oeste). O material combustível foi recolhido nas faixas demarcadas no espaço entre as árvores (Figura 1), sendo que cada faixa correspondeu a uma estação do ano (verão, inverno, outono e primavera), nas quais foram demarcadas 15 parcelas de forma sistemática. A parte experimental de campo teve início no inverno de 2007 (mês de junho) e término no outono de 2008 (mês de maio) e em cada estação foram coletadas amostras durante 15 dias, em um intervalo de coleta de 5 dias, no período das 12 às 14 horas, sendo quatro diariamente, de forma alternada nas unidades amostrais de $30 \times 30 \mathrm{~cm}$, perfazendo 60 amostras por estação do ano e 240 no final de todas as estações.

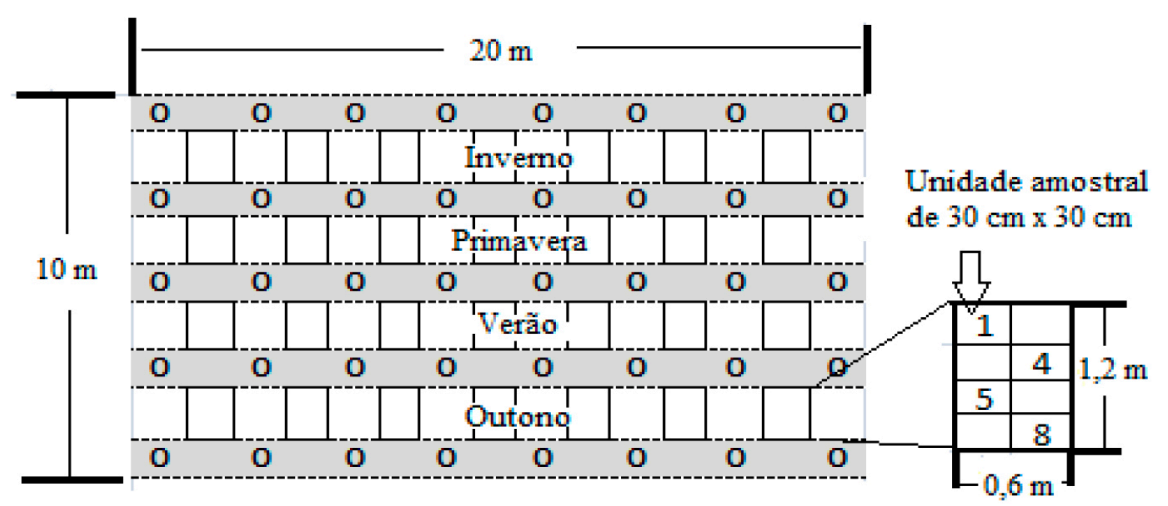

FIGURA 1: Área de amostragem e as respectivas parcelas e sub-parcelas (unidades amostrais). FIGURE 1: Sampling area and their plots and sub-plots (sample unities). 
As atividades foram planejadas com base na previsão do tempo e em dados históricos da precipitação da estação meteorológica localizada no município da Lapa - PR, no período de 2001 a 2006. Essa informação foi utilizada para prever o melhor período de coleta das amostras, com base no comportamento dos índices de perigo de incêndios: Fórmula de Monte Alegre (FMA) e Fórmula de Monte Alegre Alterada $\left(\mathrm{FMA}^{+}\right)$, que apresentam relação com a umidade do material combustível. Após a retirada da biomassa nas subunidades amostrais, foi medida a espessura da manta morta litter. $\mathrm{O}$ valor da mesma correspondeu à média das medições nas quatro laterais da camada removida. O material combustível foi agrupado em classes diamétricas, conforme a metodologia proposta por Brown, Oberheu e Johnston (1982), tendo apresentado apenas as classes: i. A, que correspondeu às folhas e aos ramos (acículas) com espessura até $0,7 \mathrm{~cm}$; e ii. B, com espessura de $0,71 \mathrm{a} 2,5 \mathrm{~cm}$, caracterizada por conter basicamente ramos. Aqueles que possuíam diâmetro superior a $2,5 \mathrm{~cm}$ não foram amostrados, por apresentarem maior amplitude dos teores de umidade, não representando perigo para ocorrência de incêndios (BEUTLING, 2009). A classe A foi subdividida em três subclasses: camada superior (AA) - formada por folhas e ramos, que compreende acículas menos decompostas de cor marrom-clara e com brilho, indicativo de ter caído recentemente; camada intermediária $(\mathrm{AB})$ - composta por folhas e ramos, incluindo acículas de coloração marrom, sem brilho, com pouca rigidez, apresentando indícios do início de decomposição; e camada inferior (AC) - formada por folhas de coloração marrom-escura, em processo de decomposição avançado e com baixa rigidez. Posteriormente, o material foi retirado, acondicionado em sacos plásticos, identificado e enviado ao laboratório de ciências da madeira da UFPR.

\section{Análises laboratorias}

\section{Teor de umidade (base seca)}

No laboratório, foram determinadas as massas das amostras (base úmida), transferidas para embalagens de papel kraft e colocadas em estufa para secagem a uma temperatura de $75^{\circ} \mathrm{C}$, durante 72 horas. Posteriormente, foram determinadas as massas (seca), logo após a retirada da estufa. O teor de umidade foi determinado conforme a norma ABNT NBR 8293 (1986b), por meio da equação 01:

$$
\mathrm{UMC}=\frac{\mathrm{M}_{\mathrm{u}}-\mathrm{M}_{\mathrm{s}}}{M_{\mathrm{s}}} * 100
$$

Em que: $\mathrm{UMC}=$ teor de umidade do material combustível (base seca), em porcentagem (\%); $\mathrm{M}_{\mathrm{u}}=$ massa do material úmido, em gramas $(\mathrm{g}) ; \mathrm{M}_{\mathrm{s}}=$ massa do material seco, em gramas $(\mathrm{g})$.

\section{Composição química imediata}

Para análise do poder energético, foi considerada a época que mostrou superioridade pelo teste de comparação das médias, tendo sido descartadas as restantes. Foram escolhidas de forma aleatória quatro amostras (repetições) para cada tratamento (AA, $\mathrm{AB}, \mathrm{AC}$ e B). Foi utilizado o número mínimo de repetições, de modo a economizar os custos de análises laboratoriais. Os parâmetros de composição química imediata (teor de material volátil, carbono fixo e cinzas) foram determinados com base na norma ABNT NBR 8112 (1986a).

\section{Poder calorífico superior e densidade energética}

Foi usada uma bomba calorimétrica automática, marca IKA WORKS (modelo C5000), com princípio de funcionamento adiabático, isoperibólico ou dinâmico para determinar o Poder Calorífico Superior (PCS) 
do combustível florestal, conforme norma padrão ABNT NBR 8633 (1984). A estimativa da densidade energética da manta por hectare foi determinada usando a equação 02 .

$$
\rho \mathrm{e}=\text { PCS* MA }
$$

Em que: $\rho e=$ densidade energética da manta, em kcal.ha ${ }^{-1} ; \mathrm{PCS}=$ Poder Calorífico Superior, em kcal.kg-1 (base seca); MA = quantidade de biomassa seca, em kg.ha ${ }^{-1}$.

\section{Análise de dados}

Os dados foram organizados em planilha excel e analisados com auxílio do software Assistat 7. Foi considerada a melhor época de coleta da biomassa, a média amostral que apresentou maior massa seca e baixo teor de umidade. Para tal, foi realizado o teste de homogeneidade (teste de Bartlett), seguida de Análise de Variância (ANOVA) e, por último, o teste de comparação de médias (teste de Tukey), para comparação das médias da biomassa e da umidade das amostras entre as épocas de coleta. As análises laboratoriais subsequentes foram realizadas usando as amostras da época que mostrou superioridade pelo teste de média (baixo teor de umidade e maior quantidade de massa seca). Foi aplicado ANOVA e teste de média, com os resultados da composição química imediata e Poder Calorífico Superior, com vistas a encontrar a melhor classe de material que pode ser utilizada para conversão em bioenergia.

\section{RESULTADOS E DISCUSSÃO}

\section{Época de coleta}

A espessura média da manta ao longo das quatro estações do ano foi de $15,05 \mathrm{~cm}$, tendo apresentado uma variação de 14,8 a $15,3 \mathrm{~cm}$. O valor médio da espessura foi superior a de outros trabalhos realizados em cultivos de Pinus, provavemente devido à idade avançada do cultivo e à ausência de tratamentos silviculturais. Batista (1995), por exemplo, trabalhando em cultivos de P. taeda de 13 anos de idade no norte do estado do Paraná, encontrou valor médio de 5,3 cm. Segundo Trevisan et al. (1987), essa variável depende da idade, espécie, condições de decomposição e qualidade do sítio.

Na Tabela 1 são apresentados os resultados do teste de Tukey e os respectivos desvios padrões das variáveis: umidade dos combustíveis e da massa seca. A classe AA apresentou menor teor e baixa variação de umidade em todas as épocas, diferindo das demais classes, provavelmente devido a sua maior exposição às variáveis meteorológicas. Na mesma classe (AA), as épocas de inverno $(38,98 \mathrm{~b})$ e primavera $(40,53 \mathrm{~b})$ apresentaram-se como as melhores para coleta comparativamente às demais em termos de umidade do material. O baixo teor de umidade contido no material da classe AA nessas épocas é um bom indicativo da sua pontencialidade para conversão em energia, devido à menor quantidade de calor necessária para ignição do material, considerando que o teor de umidade da biomassa para fins energéticos não pode ultrapassar os 50\% (NOGUEIRA et al., 2000; CORTEZ; LORA; GÓMEZ, 2008). Para fins de combustão em equipamentos apropriados, o ideal seria utilizar biomassa com teor de umidade abaixo dos $20 \%$ (VALE et al., 2011). 
TABELA 1: Massa seca e umidade em função das classes do material nas diferentes épocas em que o estudo foi conduzido.

TABLE 1: Dry weight and moisture according to the class of the material in the different seasons in which the study was conducted.

\begin{tabular}{|c|c|c|c|c|c|c|c|c|c|}
\hline \multirow{3}{*}{ Variável } & \multirow{3}{*}{ Época } & \multicolumn{8}{|c|}{ Classes do material } \\
\hline & & \multicolumn{2}{|c|}{ AA } & \multicolumn{2}{|c|}{$\mathrm{AB}$} & \multicolumn{2}{|c|}{$\mathrm{AC}$} & \multicolumn{2}{|l|}{ B } \\
\hline & & Méd & $\mathrm{Sd}$ & Méd & $\mathrm{Sd}$ & Méd & $\mathrm{Sd}$ & Méd & $\mathrm{Sd}$ \\
\hline \multirow{4}{*}{$\begin{array}{l}0 \\
\frac{0}{0} \\
\frac{0}{\pi} \\
\frac{\pi}{g} \\
5\end{array}$} & Inverno & $38,98 \mathrm{bB}$ & 18,23 & $167,61 \mathrm{bA}$ & 60,58 & $159,36 \mathrm{bA}$ & 23,93 & $158,51 \mathrm{cA}$ & 54,49 \\
\hline & Primavera & $40,53 \mathrm{bC}$ & 33,90 & $164,68 \mathrm{bB}$ & 55,65 & $241,52 \mathrm{aA}$ & 38,00 & $211,16 \mathrm{bcB}$ & 66,84 \\
\hline & Verão & $75,26 \mathrm{aC}$ & 39,17 & $209,63 \mathrm{aB}$ & 39,74 & $243,14 \mathrm{aA}$ & 48,01 & $211,16 \mathrm{aB}$ & 63,09 \\
\hline & Outono & $67,09 \mathrm{aC}$ & 25,37 & $191,14 \mathrm{aB}$ & 53,86 & $229,55 \mathrm{aA}$ & 62,64 & $186,72 \mathrm{bB}$ & 74,91 \\
\hline \multirow{4}{*}{ 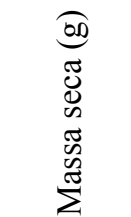 } & Inverno & $44,89 \mathrm{aC}$ & 7,07 & $124,56 \mathrm{aB}$ & 25,10 & $310,91 \mathrm{aA}$ & 73,78 & $54,41 \mathrm{aC}$ & 24,81 \\
\hline & Primavera & $45,69 \mathrm{aC}$ & 6,72 & $109,08 \mathrm{bB}$ & 14,35 & $254,89 \mathrm{bA}$ & 42,74 & $40,41 \mathrm{abC}$ & 22,06 \\
\hline & Verão & $31,63 \mathrm{aC}$ & 5,26 & 96,78 bB & 20,15 & $236,39 \mathrm{cA}$ & 18,08 & $41,50 \mathrm{abC}$ & 53,15 \\
\hline & Outono & $42,39 \mathrm{aC}$ & 7,20 & $99,28 \mathrm{bB}$ & 15,61 & $229,18 \mathrm{cA}$ & 46,67 & $36,59 \mathrm{bC}$ & 17,38 \\
\hline
\end{tabular}

Coeficiente de variação $(\mathrm{CV} \%)=13,33$

Diferença Mínima Significativa nas Linhas (D.M.S Linhas $)=26,48$

Diferença Mínima Significativa nas Colunas (D.M.S $\left.\mathrm{S}_{\text {Colunas }}\right)=23,48$

Fcal $=490,32 * *$

Em que: $\mathrm{AA}, \mathrm{AB}$ e $\mathrm{AC}=$ Camandas superior, intermediárea e inferior do material da classe $\mathrm{A}, \mathrm{B}=$ Material da classe $\mathrm{B}$ com diâmetro entre 0,71 a $2,5 \mathrm{~cm}$; Méd = média, $\mathrm{Sd}=$ desvio padão; Letras maiúsculas nas linhas e minúsculas nas colunas. Médias iguais não diferem estatisticamente pelo teste de Tukey.

Observou-se que aproximadamente $75 \%$ de todo o material amostrado pertencia à classe de acículas e galhos finos $(\leq 0,7 \mathrm{~cm})$, compostas pelas subclasses $\mathrm{AA}, \mathrm{AB}$ e $\mathrm{AC}$. Resultados semelhantes foram encontrados por Pérez-Suárez et al. (2009) ao analisarem a disponibilidade de combustíveis florestais em cultivos de Quercus potosina e Pinus cembroide de $80 \pm 8$ anos de idade, com densidade de $2.325 \pm$ 193 indivíduos por hectare para $Q$. potosina e $950 \pm 185$ para $P$. cembroides, em florestas semiáridas do México central, tendo encontrado quantidades de deposição de serrapilheira de aproximadamente 4.869 $\pm 510 \mathrm{~kg} \cdot \mathrm{ha}^{-1} \cdot$ ano $^{-1} \mathrm{em}$ cultivos de Q. potosina e $3.023 \pm 337 \mathrm{~kg} \cdot \mathrm{ha}^{-1} \cdot$ ano $^{-1}$ para $P$. cembroides. Os autores discorrem que dessas quantidades, $60 \%$ era composta por acículas, enquanto os ramos finos totalizaram 20 $30 \%$ do material coletado. Igualmente, Batista (1995) observou que aproximadamente $80 \%$ do combustível em um cultivo de Pinus taeda de 13 anos de idade, localizado no norte do estado do Paraná, era composto por material da classe A. As proporções entre as classes A e B estão de acordo com as encontradas por outros autores, cabendo destacar que os valores elevados de material da classe A possam estar relacionados com o tempo de permanência no solo, após a queda destes.

Com relação à disponibilidade do material, observaram-se maiores quantidades no inverno, sendo a média superior às restantes, exceto na classe $\mathrm{AA}$ em que não foram observadas diferenças entre as médias nas estações do ano. Estudo sobre o aporte de serrapilheira em uma floresta com três estágios sucessionais (inicial, médio e avançado), localizada no município de Pinheiral, no estado do Rio de Janeiro, realizada por Menezes et al. (2010), encontrou maiores quantidades de serrapilheira nos meses do inverno (julho e agosto), correspondendo também ao período de maior disponibilidade de combustíveis florestais no presente estudo.

Observou-se que nas épocas em que o teor de umidade do material combustível foi maior, como no caso do verão, a disponibilidade dos combustíveis diminuiu, quase em proporção inversa. Esse fato, provavelmente está relacionado à variação das condições meteorológicas do local, visto que o inverno 
foi a época em que se registou menor precipitação e valores baixos de umidade relativa para o período estudado. Contrariamente ao início do verão e final da primavera, a precipitação pluviométrica e a umidade relativa tenderam a ser mais acentuadas nas outras estações do ano. Pesquisa sobre a época de coleta de toras de Pinus taeda na região de Lages, estado de Santa Catarina, no sul do Brasil, realizada Brand et al. (2011), mostrou que as toras coletadas no mês de maio (início do inverno) apresentaram maior teor de umidade $(65 \%)$, comparativamente às toras coletadas no verão $(55 \%)$, primavera $(56 \%)$ e outono $(61 \%)$. É importante frisar que, embora os valores encontrados por esses autores tenham divergido com os do presente estudo, observações meteorológicas na região de Santa Catarina (Lages), no período de 2003 a 2005, registraram maior precipitação nos meses de abril a julho, coinscidindo com o início do inverno, período em que foram coletadas as toras. A umidade dos combustíveis florestais é um dos principais fatores que afetam a sua disponibilidade, os quais ganham ou perdem umidade da atmosfera e do solo em função da sua área de contato, tendendo ao equilíbrio desta variável no ambiente (HEIKKILÄ; GRÖNQVIST; JURVÉLIUS, 2007).

\section{Poder calorífico, composição química imediata e densidade energética}

$\mathrm{Na}$ Tabela 2 estão apresentados os resultados referentes às análises do potencial energético dos combustíveis florestais, sendo que a classe AC apresentou PCS $\left(3541,5 \mathrm{kcal} . \mathrm{kg}^{-1}\right)$ e teores de material volátil $(56,13 \%)$ inferiores às demais, devendo-se provavelmente ao fato dessa classe apresentar material em estado de decomposição mais avançado e com elevado teor de matéria orgânica. Em relação ao carbono fixo, embora não existam diferenças entre as médias, a classe $\mathrm{AC}$ apresentou menor teor de carbono fixo e maior quantidade de cinzas. As classes AA e B apresentaram superioridade em relação às demais em quase todas as propriedades, o que segundo Vale et al. (2007) está associado à qualidade química dos resíduos, justificando a existência de concentrações elevadas de cinzas e reduzidos teores de materiais voláteis em biomassa de baixa qualidade.

TABELA 2: Resultados das análises químicas imediata e Poder Calorífico Superior (PCS) das amostras na época do inverno.

TABLE 2: Results of immediate chemical analysis and Higher Calorific Value (PCS) of the samples in the winter season.

\begin{tabular}{ccccc}
\hline & \multirow{2}{*}{$\begin{array}{c}\text { PCS } \\
\text { Classes }\end{array}$} & \multicolumn{3}{c}{ Composição imediata } \\
\cline { 3 - 5 } & ${\left.\mathrm{kcal} . \mathrm{kg}^{-1}\right)}$ & $\mathrm{V}(\%)$ & $\mathrm{F}(\%)$ & $\mathrm{A}(\%)$ \\
\hline $\mathrm{AA}$ & $4469,00 \mathrm{a}$ & $70,91 \mathrm{a}$ & $24,06 \mathrm{a}$ & $5,03 \mathrm{bc}$ \\
$\mathrm{AB}$ & $4092,75 \mathrm{a}$ & $64,92 \mathrm{~b}$ & $25,05 \mathrm{a}$ & $10,03 \mathrm{~b}$ \\
$\mathrm{AC}$ & $3541,50 \mathrm{~b}$ & $56,13 \mathrm{c}$ & $21,72 \mathrm{a}$ & $22,15 \mathrm{a}$ \\
$\mathrm{B}$ & $4344,50 \mathrm{a}$ & $74,57 \mathrm{a}$ & $23,95 \mathrm{a}$ & $3,92 \mathrm{c}$ \\
\hline $\mathrm{F}$ & $19,16^{* *}$ & $71,70^{* *}$ & $1,27 \mathrm{n} . \mathrm{s}$. & $48,75^{* *}$ \\
D.M.S & 394,54 & 0,04 & 0,05 & 0,50 \\
CV\% & 4,57 & 2,85 & 10,48 & 23,24 \\
\hline
\end{tabular}

Em que: letras iguais não diferem estatisticamente pelo teste de Tukey. $\mathrm{V}=$ material volátil, $\mathrm{F}=$ carbono fixo e $\mathrm{A}$ $=$ cinzas). $\mathrm{D} . \mathrm{M} . \mathrm{S}=$ diferença mínima significativa; $\mathrm{CV} \%=$ coeficiente de variação; n.s. $=$ não significativo, $* *=$ significativo a $1 \%$.

Os maiores porcentuais de cinzas nas classes $\mathrm{AC}$ e $\mathrm{AB}$ estão provavelmente relacionados com a presença em quantidade e qualidade de diferentes minerais tais como o cálcio, potássio, fósforo, magnésio, ferro e sódio, visto que essas camadas encontram-se em estado mais avançado de decomposição e em contato com o matéria orgânica do solo. Porcentuais de cinzas elevados não constituem problema na queima de biomassa, já que existem caldeiras com grelhas e sistema autolimpante para eliminação de excesso de cinzas (VALE et al., 2007). Paralelamente, foi observado que não existem diferenças entre PCS das classes 
$\mathrm{AA}, \mathrm{AB}$ e $\mathrm{B}$, sendo que o mesmo não se verificou em relação aos teores de cinza, em que a classe $\mathrm{B}$ apresentou menor concentração, comparativamente às restantes. $\mathrm{O} P C$ isoladamente não é suficiente para inferir sobre as qualidades energéticas de uma determinada biomassa, sendo importante ponderar outras propriedades, tais como a concentração de cinzas, materiais voláteis e composição química, dependendo da finalidade e do tipo de caldeira a ser utilizada (MUNALULA; MEINCKEN, 2009).

Ao serem comparados os valores de PCS encontrados na presente pesquisa com de outros tipos de biomassa (Tabela 3), observou-se que esses são similares aos resultados de outras pesquisas e que os trabalhos com biomassa de Pinus (JENKINS, 1990; MUNALULA; MEINCKEN, 2009; EROL; HAYKIRIACMA; KÜÇÜKBAYRAK, 2010) estão mais próximos das classes AA e B. Os porcentuais do material volátil das classes $\mathrm{AA}$ e $\mathrm{B}$, que são superiores às demais classes, estão abaixo de quase todos os valores da Tabela 3, exceto o de epicarpo, que é inferior ao da classe B. Valores semelhantes foram encontrados por González et al. (2005) trabalhando com casca de amêndoa, resíduos florestais e de poda, sendo que o material volátil variou de 71 a $83 \%$, cinzas de 0,6 a 5\%, carbono fixo de 14 a 16\% e PCS de 3821,60 a $4418,72 \mathrm{kcal} . \mathrm{kg}^{-1}$.

TABELA 3: Poder Calorífico Superior (PCS) e composição química imediata de alguns tipos de biomassa.

TABLE 3: Higher Calorific Value (PCS) and immediate chemical analysis of some types of biomass.

\begin{tabular}{|c|c|c|c|c|c|}
\hline \multirow{2}{*}{ Tipo de biomassa } & \multirow{2}{*}{$\begin{array}{c}\text { PCS (kcal. } \\
\left.\mathrm{kg}^{-1}\right)\end{array}$} & \multicolumn{3}{|c|}{ Composição imediata } & \multirow{2}{*}{ Fonte } \\
\hline & & V (\%) & $\mathrm{F}(\%)$ & $\mathrm{A}(\%)$ & \\
\hline Pinus & $4.781,78$ & 82,54 & 17,70 & 0,29 & \multirow{3}{*}{ Jenkins (1990) } \\
\hline Eucalyptus & $4.638,46$ & 81,42 & 17,82 & 0,79 & \\
\hline Sabugo de milho & $4.483,21$ & 80,10 & 18,54 & 3,60 & \\
\hline Casca de café & $3.933,00$ & 75,73 & 10,31 & 13,96 & Vale et al. (2007) \\
\hline Epicarpo & $3.461,00$ & 72,60 & 13,00 & 14,43 & \multirow{2}{*}{ Vale et al. (2011) } \\
\hline Torta & $5.122,00$ & 77,40 & 45,50 & 7,95 & \\
\hline Vagem de soja & $4.029,00$ & 76,61 & 18,24 & 7,25 & \multirow[t]{2}{*}{$\begin{array}{l}\text { Paula, Trugilho e } \\
\text { Bianchi (2011) }\end{array}$} \\
\hline Vagem de feijão & $4.218,53$ & 76,65 & 18,10 & 4,61 & \\
\hline Acacia cyclops & $4.535,76$ & ----- & ----- & 2,15 & \multirow{3}{*}{$\begin{array}{c}\text { Munalula e } \\
\text { Meincken (2009) }\end{array}$} \\
\hline Pinus patula & $4.461,72$ & ---- & ---- & 0,45 & \\
\hline $\begin{array}{l}\text { Eucalyptus } \\
\text { cladocalyx }\end{array}$ & $4.507,10$ & ----- & ----- & 2,38 & \\
\hline Cone de pinus & $4.430,85$ & 77,16 & 15,15 & 6,89 & \multirow{2}{*}{$\begin{array}{c}\text { Erol, Haykiri-Acma } \\
\text { e Küçükbayrak } \\
\text { (2010) }\end{array}$} \\
\hline Carroço de pêssego & $4.662,35$ & 78,16 & 20,79 & 1,05 & \\
\hline
\end{tabular}

Em que: $\mathrm{V}=$ material volátil, $\mathrm{F}=$ carbono fixo e $\mathrm{A}=$ cinzas .

Os resultados referentes à disponibilidade do material combustível (MA), em quilogramas por

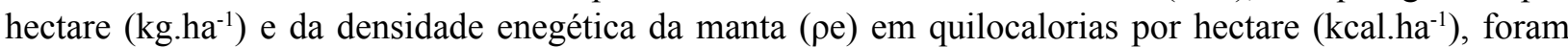
apresentados na Tabela 4, observando-se que, embora as classes AA e B tenham maior potencial para produção de energia (PCS), as mesmas possuem menor densidade energética, devido à baixa quantidade de material disponível. 
TABELA 4: Densidade energética da manta ( $\rho$ e) $\left(\mathrm{kcal}_{\mathrm{ha}} \mathrm{h}^{-1}\right)$.

TABLE 4: Energy density of the above ground litterfall ( $\rho$ e) $\left(\mathrm{kcal}^{\mathrm{k}} \mathrm{ha}^{-1}\right)$.

\begin{tabular}{ccc}
\hline Classes & Material combustível $\left(\mathrm{kg}^{\mathrm{ha}} \mathrm{h}^{-1}\right) \cdot 10^{3}$ & $\mathrm{\rho e}\left(\mathrm{kcal}^{\mathrm{ha}} \mathrm{a}^{-1}\right) \cdot 10^{5}$ \\
\hline $\mathrm{AA}$ & 5,00 & 222,90 \\
$\mathrm{AB}$ & 13,84 & 566,44 \\
$\mathrm{AC}$ & 34,55 & $1.223,43$ \\
$\mathrm{~B}$ & 6,00 & 262,65 \\
\hline TOTAL & 59,39 & $2.275,42$ \\
\hline
\end{tabular}

Não obstante as classes AAe B terem apresentado menor densidade energética, no caso de necessidade de conversão em bioenergia, o sistema é viável, visto que haverá menor custo de transporte, devido à baixa quantidade de umidade contida nela e maior poder energético, bem como, porcentagem considerável de material volátil, teor de cinzas baixo e elevado PCS. Valores de potencial energético semelhantes aos encontrados nesse estudo foram reportados por Vale et al. (2007), que encontraram $3.933 .000 \mathrm{kcal}$ por tonelada e comentaram que essa quantidade de energia seria suficiente para gerar calor em fornalhas ou mesmo energia elétrica em pequenas comunidades.

\section{CONCLUSÃO}

Os resultados encontrados no presente estudo permitiram concluir que existe potencial para converter combustíveis florestais em biomassa energética, contribuindo para reduzir o perigo de incêndios florestais. Com baixos teores de umidade e maior quantidade de biomassa disponível, as épocas de inverno e primavera foram as melhores para a colheita de biomassa.

A análise do Poder Calorífico Superior (PCS) e da composição química imediata permitiu concluir que o material das classes AA e B apresentaram maior potencial energético em relação às demais classes e melhor qualidade energética, se comparado a outros tipos de biomassa. A densidade energética por hectare é consideravelmente suficiente para conversão em energia.

\section{REFERÊNCIAS}

ASSOCIAÇÃO BRASILEIRA DE NORMAS TÉCNICAS. NBR 8112: análise imediata. Rio de Janeiro, 1986a.

ASSOCIAÇÃO BRASILEIRA DE NORMAS TÉCNICAS. NBR 8293: determinação de umidade. Rio de Janeiro, 1986b.

ASSOCIAÇÃO BRASILEIRA DE NORMAS TÉCNICAS. NBR 8633: determinação do poder_calorífico superior. Rio de Janeiro, 1984.

AL-HAMAMRE, Z. et al. Wastes and biomass materials as sustainable-renewable energy resources for Jordan. Renewable and Sustainable Energy Reviews, [S.1.], v. 67, p. 295-314, 2017.

BATISTA, A. C. Avaliação da queima controlada em povoamentos de Pinus taeda L. no norte do Paraná. Curitiba. 1995. 108 f. Tese (Doutorado em Engenharia Florestal) - Setor de Ciências Agrárias, Universidade Federal do Paraná, Curitiba, 1995.

BEUTLING, A. Combustíveis florestais. In: SOARES, R. V.; BATISTA, C. A.; NUNES, J. R. S. Incêndios florestais no Brasil: o estado da arte. Curitiba: [s. n.], 2009. p. 21-34.

BRAND, M. A. et al. Storage as a tool to improve wood fuel quality. Biomass and Bioenergy, Oxford, n. 35, p. 2583-2588, 2011.

BRASIL. Ministério de Minas e Energia. Plano nacional de energia 2030. Brasília: MME, 2007. Disponível em: <http://www.epe.gov.br/PNE/20080512_8.pdf >. Acesso em: 3 maio 2013.

BROWN, J. K.; OBERHEU, R. D.; JOHNSTON, C. M. Handbook for inventorying surface fuels and biomass in the Interior West. Ogden: Intermountain Forest and Range Experiment Station, 1982. 48 p. 
CHOI, S.; CHAMG, Y.; PARK, B. Increase in carbon emissions from forest after intensive reforestation and management programs. Science of the Environment, [S.1.], v. 371, p. 225-235, 2006.

CORTEZ, L. A. B.; LORA, E. S.; GÓMEZ, E. O. Biomassa para energia. Campinas: Unicamp, 2008. 733 p.

ENERGY INFORMATION ADMINISTRATION. Annual energy outlook 2013 with projections to 2040. Washington: EIA, 2013. Disponível em: <http://www.eia.gov/forecasts/aeo/>. Acesso em: 08 jul. 2013. ENERGY INFORMATION ADMINISTRATION. International Energy Outlook 2017. Washington: EIA, 2017. Disponível em: <https://www.eia.gov/outlooks/ieo/pdf/0484(2017).pdf>. Acesso em: 16 out. 2017.

EROL, M.; HAYKIRI-ACMA, H.; KÜÇÜKBAYRAK, S. S. Calorific value estimation of biomass from their proximate analyses data. Renewable Energy, Oxford, v. 35, n. 1, p. 170-173, 2010.

FULLER, M. Forest fires: an introduction to wildland fire behavior, management, firefighting, and prevention. New York: J. Wiley \&Sons, 1991.

GONZÁLEZ, J. F. et al. Use of almond residues for domestic heating. Study of the combustion parameters in a mural boiler. Fuel Processing Technology, Amsterdam, v. 86, p. 1351-1368, 2005.

HEIKKILÄ, T. V.; GRÖNQVIST, R.; JURVÉLIUS, M. Wildland fire management: handbook for trainers. Helsinki: Ministry for Foreign Affairs of Finland; Development Policy Information Unit, 2007. 248 p.

INDÚSTRIA BRASILEIRA DE ÁRVORES. Relatório Anual Indústria Brasileira de Árvores 2016. Brasília: IBÁ, 2016. Disponível em: < http://iba.org/images/shared/Biblioteca/IBA_RelatorioAnual2016_. pdf $>$. Acesso em: 16 out. 2017.

INTERNATIONAL RENEWABLE ENERGY AGENCY. REthinking Energy 2017. Abu Dhabi: IRENA, 2017. Disponível em: <https://www.irena.org/DocumentDownloads/Publications/IRENA_REthinking _ Energy_2017.pdf $>$. Acesso em: 16 out. 2017.

JENKINS, B. M. Fuel properties for biomassa materials. In: INTERNATIONAL SYMPOSIUM ON APPLICATION AN MANAGEMENT OF ENERGY IN AGRICULTURE: THE ROLE BIOMASS FUELS, 1990, New Delhi. Proceedings... Ludhiana: Punjab Agricultural University, 1990. p. 21-23.

MAACK, R. Geografia física do estado do Paraná. 3. ed. Curitiba: Imprensa Oficial, 2002. 440 p.

MENEZES, C. E. et al. Aporte e decomposição de serapilheira e produção de biomassa radicular em florestas com diferentes estágios sucessionais em Pinheiral, RJ. Ciência Florestal, Santa Maria, v. 20, n. 3, p. 439-452, jul./set. 2010.

MUNALULA, F.; MEINCKEN, M. An evaluation of South African fuelwood with regards to calorific value and environmental impact. Biomass and Bioenergy, Oxford, v. 33, n. 3, p. 415-420, 2009.

NOGUEIRA, L. A. H. et al. Drendroenergia: fundamentos e aplicações. Rio de Janeiro: [s. n.], 2000. 144 p.

NOGUEIRA, L. A. H.; LORA, E. E. Wood energy: principles and applications. Itajubá: Núcleo de excelência de geração termoelétrica distribuída, 2002. Disponível em: <http://www.nest.unifei.edu.br/ english/pags/downloads/files>. Acesso em: 25 ago. 2013.

ÖZYUĞURAN, A.; YAMAN, S. Prediction of calorific value of biomass from proximate analysis. Energy Procedia, [S.1.], v. 107, p. 130-136, 2017.

PAHLA, G. et al. Energy densification of animal waste lignocellulose biomass and raw biomass. South African Journal of Chemical Engineering, Amsterdam, v. 24, p. 168-175, dec. 2017. Disponível em: $<$ http://linkinghub.elsevier.com/retrieve/pii/S102691851730046X>. Acesso em: 16 out. 2017.

PÉREZ-SUÁREZ, M. et al. Production and quality of senesced and green litterfall in a pine-oak forest in central-northwest Mexico. Forest Ecology and Management, Amsterdam, v. 258, p. 1307-1315, 2009.

PAULA, L. E. R.; TRUGILHO, P. F.; BIANCHI, M. L. Characterization of residues from plant biomass for use in energy generation. Cerne, Lavras, v. 17, n. 2, p. 237-246, 2011.

ROSILLO-CALLE, F.; BAJAY, S. V.; ROTHMAN, H. Uso da biomassa para produção de energia na indústria brasileira. Campinas: Unicamp, 2005. $447 \mathrm{p}$.

SOUZA, M. M. Caracterização e viabilidade econômica do uso energético de resídos da colheita florestal e do processamento de Pinus taeda L. 2010. 77 f. Dissertação (Mestrado em Engenharia Florestal) - Universidade Federal do Paraná, Curitiba, 2010.

TOKLU, E. Biomass energy potential and utilization in Turkey. Renewable Energy, Oxford, v. 107, p. 
235-244, 2017.

TREVISAN, E. et al. Morfologia de horizontes orgânicos acumulados sob povoamentos de Pinus taeda L. em três sítios distintos. Ciências Agrárias, Curitiba, v. 9, p. 59-62, 1987.

VALE, A. T. et al. Caracterização energética e rendimento da carbonização de resíduos de grãos de café (Coffea arabica, L) e de madeira (Cerelinga catenaefornis). Cerne, Lavras, v. 13, n. 4, p. 416-420, 2007.

VALE, A. T. et al. Potencial energético da biomassa e carvão vegetal e da torta de pinhão-manso (Jatropha curcas). Cerne, Lavras, v. 17, n. 2, p. 267-273, 2011.

WU, Q. et al. Sustainable and renewable energy from biomass wastes in palm oil industry: a case study in Malaysia. International Journal of Hydrogen Energy, Oxorford, v. 42, n. 37, p. 23871-23877, 2017. 